\title{
Association between respiratory and postural adaptations and self-perception of school-aged children with mouth breathing in relation to their quality of life
}

Suélen E. Uhlig ${ }^{1}$, Laís M. Marchesi ${ }^{1}$, Halina Duarte ${ }^{1}$, Maria T. M. Araújo ${ }^{2}$

\begin{abstract}
Objective: To investigate the respiratory and postural adaptations associated with mouth and nasal breathing and to evaluate the associations of such adaptations in mouth breathers' self-perceived quality of life. Method: Crosssectional study with mouth breathers (initial $n=116$ and final $n=48$ ) and nasal breathers (initial $n=131$ and final $n=24$ ) from elementary school, aged between 7 and 14 years. Chest expansion, using cirtometry, the breathing pattern and the use of accessory muscles, by means of clinical evaluations and photogrammetry, and flexibility tests were evaluated in both groups. Subsequently, the mouth breathers were asked to complete the quality of life questionnaire. Statistical tests: Chi-square, odds ratio, Mann-Whitney, and binomial tests were first applied followed by logistic regressions. Results: Thoracic breathing $(p=0.04)$, using of accessory muscles $(p=0.03)$ and reductions in flexibility $(p=0.001)$ increased the chances of an individual being a mouth breather when compared to nasal breathers. Subsequently, using of accessory muscles decreased the chances of snoring among mouth breathers $(p=0.03)$; the presence of shoulder asymmetry reduced the chances of experiencing quiet sleep $(p=0.05)$ and increased the chances of coughing or being tired when playing or running $(p=0.008)$. Finally, forward head position reduced the chances of waking up at night $(p=0.04)$ and experiencing shortness of breath $(p=0.05)$. Conclusions: Respiratory and postural adaptations increased the chances of individuals persisting with mouth breathing. Additionally, these adaptations could be associated with mouth breathers' self-perceived quality of life.
\end{abstract}

Keywords: preschool; mouth breathing; postural adaptations; self-perceived; quality of life; physical therapy.

\section{HOW TO CITE THIS ARTICLE}

Uhlig SE, Marchesi LM, Duarte H, Araújo MTM. Association between respiratory and postural adaptations and self-perception of school-aged children with mouth breathing in relation to their quality of life. Braz J Phys Ther. 2015 May-June; 19(3):201-210. http://dx.doi.org/10.1590/bjpt-rbf.2014.0087

\section{Introduction}

During mouth breathing (MB), accessory muscle overuse leads to a predominance of chest wall motion during inspiration ${ }^{1,2}$, and forward head posture (FHP) is the most commonly adopted postural compensation among MB individuals ${ }^{3}$. Okuro et al. ${ }^{4}$ identified a correlation between FHP and the functional respiratory demand in MB individuals to facilitate air intake. One of the possible causes of FHP appears to be related to the overuse of accessory inspiratory muscles ${ }^{5}$. Persistent FHP can affect the entire body's posture due to the synergistic action of the head and neck muscles ${ }^{6,7}$. Some studies have reported that head, neck and shoulder girdle muscle overuse can trigger secondary muscle weakness and promote shoulder asymmetry, which are signs of changes in the curvatures of the vertebral column $^{6,8}$. Furthermore, such weakness could be due to changes in the myofascial meridians, which, together, are responsible for maintaining stability and discriminating how myofascial tension is distributed throughout the body during movement ${ }^{9}$. Thus, changes in posture, imbalance and muscle shortening influence the flexibility of certain muscle groups ${ }^{10}$.

Depending on its duration, MB can cause functional, structural, pathological, postural, occlusive and behavioral changes. Most studies on MB have focused on clinical aspects ${ }^{1,4,6,8}$. Only in recent decades have behavioral aspects, such as hyperactivity, nonrestorative sleep, nocturnal enuresis, irritability, headache, and difficulties in concentrating and learning, been investigated as factors that impact the quality of life of MB individuals ${ }^{11-14}$. Most studies evaluate these behavioral changes by means of various questionnaires ${ }^{13,14}$, including those related to quality of life ${ }^{15,16}$. Popoaski et al. ${ }^{16}$ developed a quality of life questionnaire exclusively for MB individuals and demonstrated that MB had a negative impact on the

\footnotetext{
${ }^{1}$ Departamento de Educação Integrada em Saúde, Universidade Federal do Espírito Santo (UFES), Vitória, ES, Brazil 
quality of life, especially with respect to behavioral aspects and respiratory disorders.

However, few studies have associated clinical evaluations and the quality of life of MB students, especially regarding their self-perception. Thus, the present study aimed to evaluate possible respiratory and postural adaptations of predominantly MB students compared to their predominantly nasal breathing (NB) peers and to subsequently associate the results obtained for the MB group with aspects regarding their self-perceived quality of life. The study was divided into two stages. The first stage assessed the prevalence and chances of respiratory and postural adaptations in MB students compared to their NB peers. The second stage evaluated the chances of respiratory and postural adaptations being risk or protective factors for the self-perceived quality of life of MB students, specifically regarding sleep, school performance, atopy and nasal problems.

\section{Method}

This study was a clinical cross-sectional study approved by the Ethics Committee of the Universidade Federal do Espirito Santo (UFES), Vitória, ES, Brazil (Protocol nr. 162/2009) that was authorized by the Municipality Government of Vitória, Municipal Secretariat of Education, Vitória, ES, Brazil (Protocol nr. 281/2010). Ten elementary schools were randomly selected, and the inclusion criteria were as follows: students aged 7 to 14 years, previously screened and classified as mouth breathers by physicians and dentists ( $n=116)$, providing they also exhibited four or more of the ten craniofacial changes (described in the flowchart - Figure 1), including persistent $\mathrm{MB}$, or classified as nose breathers $(n=131)$ if they exhibited less than four or none of the above changes. Exclusion criteria were as follows: students whose parents did not sign the informed consent form prior to or during the study and students older than 12 years who did not sign the informed consent form at the beginning of the study; and students with craniofacial malformations, musculoskeletal, respiratory or neurological disorders. In the course of the study, the initial sample size was reduced in both groups, the causes of which are specified in the flowchart (Figure 1). The final sample size was of 24 males and 24 females $(n=48)$ in the MB group and 11 males and 13 females $(n=24)$ in the NB group.

To avoid a bias in the assessments and in the application of the questionnaire, the examiners were trained by the most experienced examiner of the team of physical therapists, who was considered the goldstandard examiner. The obtained Cohen's kappa was above 0.9 , which may be considered as an optimal agreement among the examiners of the present study ${ }^{17}$.

In the first stage of the study, the instrument used for respiratory and postural data collection was adapted from the study of Godoy et al. ${ }^{18}$. Each one of these tests was performed by physical therapists, who performed them in a blinded fashion. At each school selected, the students were randomly taken out of their classrooms by their supervisors and they underwent the same respiratory and postural evaluations in locations provided by the school. For the respiratory tests consisted of upper and lower chest expansibility, classification of the breathing pattern and identification of the use of accessory muscles. Chest expansibility was evaluated by dynamic cirtometry, using a $\mathrm{SECA}^{\circledR}$ anthropometric tape measure. The variation of maximal inspiration and expiration was measured as the circumference at the axillary and xiphoid regions. Variations between 3.0 and $7.5 \mathrm{~cm}$ were considered as normal ${ }^{19}$. The breathing pattern

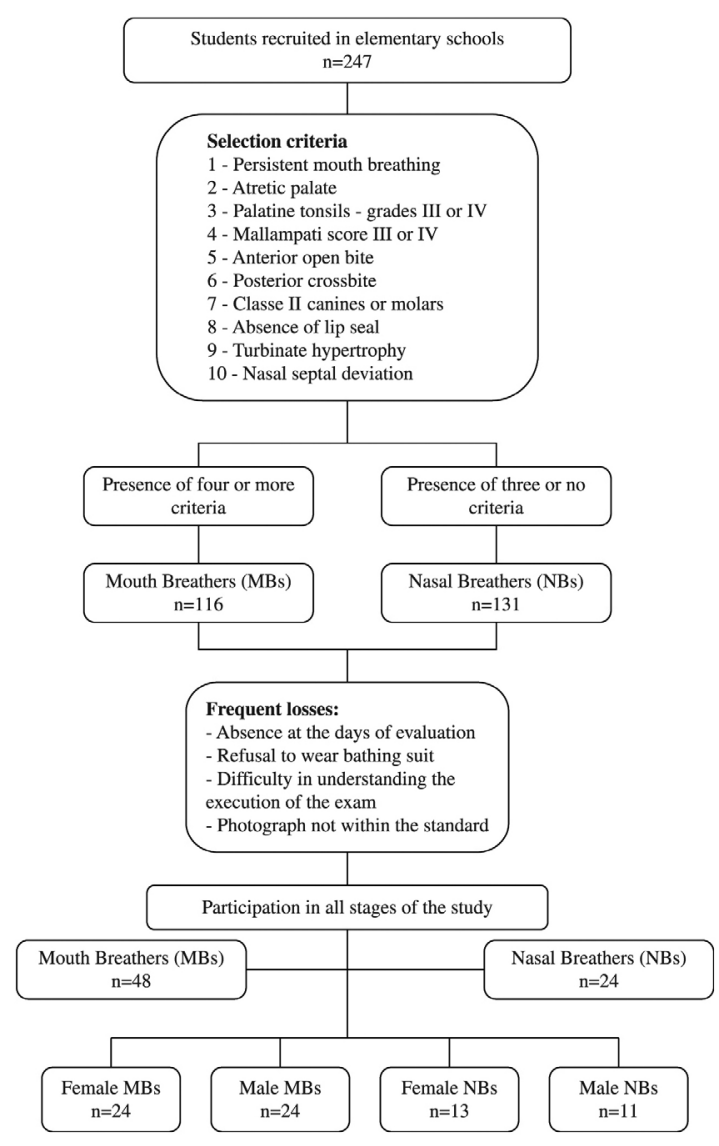

Figure 1. Flowchart of sample screening and final group composition 
and the use of accessory muscles were subjectively evaluated by visual and manual examination of the thorax. Subsequently, students were referred to a private room, in which body weight and height were assessed on a digital scale (GLASS200-G-TECH ${ }^{\circledR}$ ) and by means of an anthropometric tape measure $\left(\mathrm{SECA}^{\circledR}\right)$, respectively, to calculate the body mass index (BMI). Flexibility was assessed by means of the fingertip-to-floor (FTF) test, during which the participant was asked to bend forward in an attempt to reach the floor with the middle finger while keeping the knees straight ${ }^{18,20}$. For postural evaluation, a digital camera (Sony CyberShot 7.2 megapixels) was placed at a distance of $3.10 \mathrm{~m}$ from the wall on a 1.2-m-high tripod $^{21,22}$. Students, were photographed in an orthostatic position, while standing barefoot near a $1-\mathrm{m}$-long plumb line to their left side, on a carpet labeled with the position for their feet, which were parallel to each other. Prior to photography, anatomical landmarks were identified by the examiners using colored markers affixed with double-faced adhesive tape to the right and left acromia, the anterior superior iliac spines (ASIS) and posterior superior iliac spines (PSIS), the right and left tragus, and the 7th cervical vertebra (C7) (Figure 2). Photographs were analyzed by physical therapists using the postural analysis software $\left(\mathrm{SAPO}^{\circledR}\right.$, version 0.67$)^{23}$,in the following order: the photograph was opened, zoomed to $40 \%$, the photograph image was calibrated from the plumb line and the marked anatomical landmarks to the right and left acromia, the ASIS, the PSIS and right and left tragus, and the $\mathrm{C}^{6,24}$. In the frontal view, the lines plotted between the acromia (acromion-acromion) and between the ASISs (ASIS-ASIS) were analyzed to determine deviations of shoulders and pelvis, respectively. In the side view, the angle formed between spinous process of $\mathrm{C} 7$ with respect to the horizontal line to the chin and another until the tragus (C7-HOR-TRAGUS) and the line plotted between ASIS and PSIS (ASIS-PSIS) were analyzed to determine cervical lordosis/retification and deviations of pelvis, respectively (Figure 2). In the second stage of the study, still at school, only the MB group was studied. The instrument used was adapted from the quality of life questionnaire used in the study of Popoaski et al. ${ }^{16}$. Among the seven areas described in the study (nasal problem, sleep, eating problems, dentistry, school performance, communication and atopy), questions regarding nasal and sleep problems, atopy and school performance were applied by the physical therapists to each MB student, individually. This choice was based on the negative impacts these

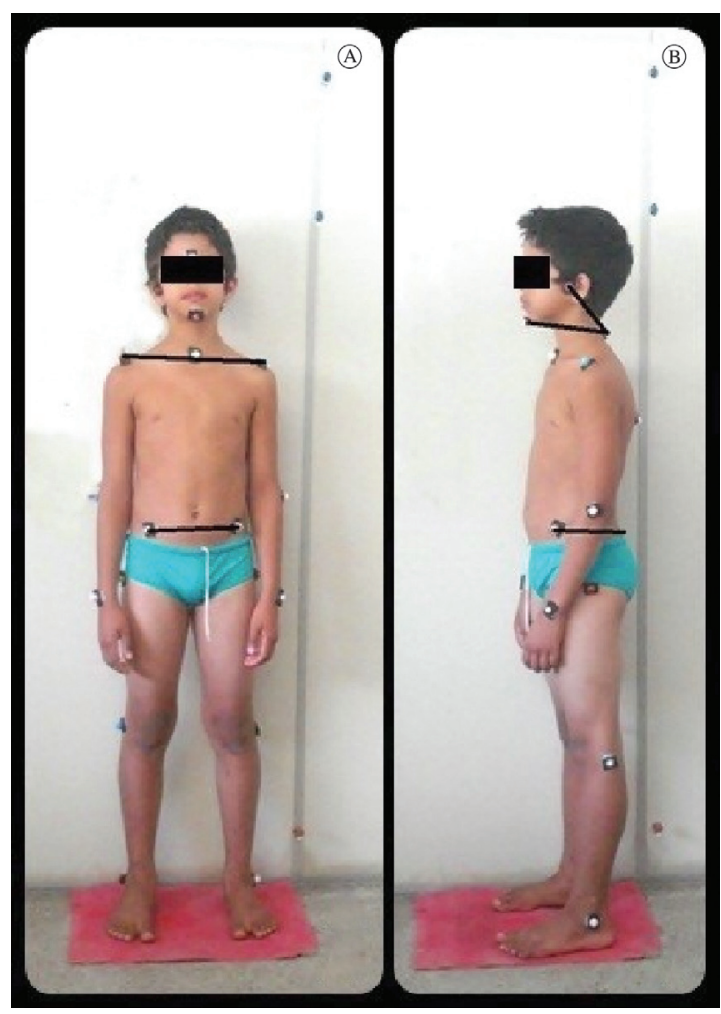

Figure 2. Photogrammetry. A) Front view: angles between the acromia and between the anterior superior iliac spines. B) Side view: angle between $\mathrm{C} 7$ with respect to a horizontal line and the tragus and the angle between the anterior superior iliac spine and the posterior superior iliac spine.

aspects had on behavior and on the breathing disorders in the individuals evaluated in their study ${ }^{16}$. The answers given by the MB students regarding the self-perceived quality of life questionnaire that corresponded to a scale ranging from "sometimes" to "always" were grouped and considered as YES, whereas answers within the range of "never" to "almost never" were grouped and considered as NO.

\section{Statistical analysis}

In the first stage of the study, Pearson's chi-squared test and the odds ratio $(\mathrm{OR})$ were calculated to evaluate the association between MB and NB groups. The Mann-Whitney $U$ test was used to assess the difference between quantitative independent variables of $\mathrm{MB}$ and NB students. The binomial and Mann-Whitney $U$ tests were used to select the variables that would be used in the logistic regression model. Specifically, the binomial test selected the variables with prevalence values equal to 0.43 or above, regardless of their statistical significance. The Mann-Whitney $U$ test 
selected the variables by comparing the median of each continuous variable versus the general median of MB and NB individuals. After selecting these variables, logistic regressions were performed to verify whether the variables selected by the binomial test (i.e. sex, breathing pattern, use of accessory muscles, cirtometry, acromion-acromion, ASIS-ASIS, C7HOR-TRAGUS, ASIS-PSIS measurements) and by the Mann-Whitney $U$ test (i.e. age, height and FTF distance measurements) were risk or protective factors when related to the selected questions of the adapted instrument of the quality of life questionnaire in the MB group. The best regression model was chosen by means of the backward method of the Wald test, which removes the variables that do not influence the model. The level of significance was set at 5\% and the confidence interval at $95 \%$. Analyses were performed using the Statistical Package for Social Sciences Software (SPSS19, IBM Company, Armonk, New York, USA).

\section{Results}

The results from the first stage revealed a statistically significant association between the MB and NB groups only with respect to respiratory variables regarding the breathing pattern and the use of accessory muscles (Table 1). Thoracic breathing increased the chances of the student being a mouth breather 3.8-fold compared to students without this pattern (NB) $(p=0.041)$. The use of altered accessory muscles increased the chances of being classified as a MB 4.2-fold compared to NB $(p=0.031)$. Table 2 shows that the medians of MB students significantly differed from those of their NB peers with respect to anthropometric variables (i.e. body weight and height), age and FTF distance measurements (flexibility) $(p<0.05)$. However, the BMI exhibited no statistically significant difference between the groups ( $p=0.27$ ).

In the second stage, some of the self-perceived aspects of the MB group, specifically regarding school

Table 1. Respiratory and postural variables of mouth breathers and nasal breathers, 7-14 years old, from the elementary schools of Vitória, ES, Brazil.

\begin{tabular}{|c|c|c|c|c|c|c|c|}
\hline \multirow{2}{*}{ Variables } & \multirow{2}{*}{ Categories } & \multicolumn{2}{|c|}{ Breathers } & \multirow{2}{*}{$\mathbf{p}$} & \multirow{2}{*}{ OR } & \multirow{2}{*}{\multicolumn{2}{|c|}{$95 \%$ CI }} \\
\hline & & Mouth & Nasal & & & & \\
\hline \multirow[t]{2}{*}{ Gender } & Female & 24 & 13 & \multirow{2}{*}{0.80} & 0.84 & 0.31 & 2.26 \\
\hline & Male & 24 & 11 & & - & - & - \\
\hline \multirow[t]{2}{*}{ Breathing pattern } & Diaphragmatic & 31 & 21 & \multirow{2}{*}{$0.04 *$} & - & - & - \\
\hline & Thoracic & 17 & 3 & & 3.83 & 0.99 & 14.75 \\
\hline \multirow[t]{2}{*}{ Accessory muscles } & No & 30 & 21 & \multirow{2}{*}{$0.03 *$} & - & - & - \\
\hline & Yes & 18 & 3 & & 4.20 & 1.09 & 16.09 \\
\hline \multirow[t]{2}{*}{ Axillary perimetry } & Normal & 42 & 18 & \multirow{2}{*}{0.66} & - & - & - \\
\hline & Reduced & 6 & 1 & & 2.57 & 0.28 & 22.92 \\
\hline \multirow[t]{2}{*}{ Xiphoid perimetry } & Normal & 41 & 18 & \multirow{2}{*}{0.42} & - & - & - \\
\hline & Reduced & 7 & 1 & & 3.07 & 0.35 & 26.84 \\
\hline \multirow{2}{*}{$\begin{array}{l}\text { Acromium to acromium } \\
\text { distance }\end{array}$} & Normal & 5 & 2 & \multirow{2}{*}{0.99} & - & - & - \\
\hline & Shoulder deviation & 43 & 22 & & 0.78 & 0.14 & 4.35 \\
\hline \multirow[t]{2}{*}{ ASIS to ASIS distance } & Normal & 4 & 3 & \multirow{2}{*}{0.67} & - & - & - \\
\hline & Pelvic deviation & 44 & 21 & & 1.57 & 0.32 & 7.66 \\
\hline \multirow[t]{2}{*}{ C7-HOR-TRAGUS distance } & Normal/rectification & 9 & 4 & \multirow{2}{*}{0.82} & - & - & - \\
\hline & Anteriorization & 39 & 20 & & 0.86 & 0.23 & 3.16 \\
\hline \multirow[t]{2}{*}{ ASIS to PSIS distance } & Normal & 1 & 0 & \multirow{2}{*}{0.99} & - & - & - \\
\hline & Anteversion or retroversion & 47 & 24 & & \# & \# & \# \\
\hline
\end{tabular}

Pearson's chi-square test. (-) Reference Category. (\#) Value not computed because one of the categories is zero. OR: odds ratio. (*) Statistically significant difference $(p<0.05)$. Reference values: variation of the axillary and xiphoid perimetry $=3.5 \mathrm{~cm}$ to $7.0 \mathrm{~cm}\left(\mathrm{Magee}{ }^{19}\right)$. Normal angle between acromia $=0^{\circ}$ and shoulder deviation $\neq 0^{\circ}$; normal angle between the anterior-superior iliac spines (ASIS-ASIS) $=0{ }^{\circ}$ and pelvic deviation $\neq 0^{\circ}$; normal angle between the antero-superior iliac spine and posterior superior iliac spine (ASIS-PSIS) $=0{ }^{\circ}$ and anteversion or retroversion pelvic $\neq 0^{\circ}$ (Iunes et al. ${ }^{25}$ ); normal or cervical rectification: the angle between the seventh cervical vertebra, horizontal line and tragus $(\mathrm{C} 7-\mathrm{HOR}-\mathrm{TRAGUS})>48.9^{\circ}$ and head anteriorization: the angle between the seventh cervical vertebra, a horizontal line and the tragus $\left(\right.$ C7-HOR-TRAGUS) $<48.9^{\circ}$ (Raine and Twomey ${ }^{26}$ ). Source: Magee ${ }^{19}$; Iunes et al. ${ }^{25}$; Raine and Twomey ${ }^{26}$. 
Table 2. Anthropometric variables and flexibility of mouth breathers and nasal breathers aged 7-14 years old, from the elementary schools of Vitória, ES, Brazil.

\begin{tabular}{|c|c|c|c|c|c|c|}
\hline Variables & $\begin{array}{c}\text { Elementary } \\
\text { school }\end{array}$ & Minimum & Maximum & Median & SD & $\mathbf{p}$ \\
\hline \multirow[t]{2}{*}{ Age (years) } & MB & 6 & 13 & 9.0 & 1.7 & \multirow{2}{*}{$0.03 *$} \\
\hline & NB & 6 & 10 & 8.0 & 1.0 & \\
\hline \multirow[t]{2}{*}{ Height (m) } & MB & 1.2 & 1.7 & 1.4 & 0.1 & \multirow{2}{*}{$0.01 *$} \\
\hline & NB & 1.2 & 1.4 & 1.3 & 0.1 & \\
\hline \multirow[t]{2}{*}{ Weight (Kg) } & MB & 18.0 & 54.0 & 30.0 & 8.7 & \multirow{2}{*}{$0.04 *$} \\
\hline & NB & 20.0 & 39.0 & 25.5 & 5.2 & \\
\hline \multirow[t]{2}{*}{ BMI } & MB & 12.0 & 27.4 & 16.3 & 3.4 & \multirow{2}{*}{0.21} \\
\hline & NB & 13.0 & 22.5 & 15.0 & 2.5 & \\
\hline \multirow{2}{*}{$\begin{array}{l}\text { Flexibility) (Middle } \\
\text { finger to floor }(\mathrm{cm}) \text { ) }\end{array}$} & MB & 0 & 33 & 11.5 & 8.3 & \multirow{2}{*}{$0.001 *$} \\
\hline & NB & 0 & 23 & 0.0 & 7.5 & \\
\hline
\end{tabular}

Mann-Whitney test. $\left({ }^{*}\right)$ Statistically significant difference $(p<0.05)$. SD: standard deviation; BMI: body mass index; MB: mouth breathers; NB: nasal breathers.

performance, atopy, sleep and nose problems, exhibited $50 \%$ or higher prevalence rates, namely: "Do you usually have a stuffed nose?" (79.2\%); "Do you usually have a runny nose?" (50.0\%); "Do you usually wake up at night?" (60.4\%); "Are you usually sleepy during the day?" (52.1\%); "Is your sleep usually quiet?" (87.5\%); "Do you usually wake up with a headache?" (58.3\%); "Do you usually wake up with a dry mouth?" (77\%); "Do you usually cough when you lie down?" (56.3\%); "Do you usually cough or get tired when you play/run?" (79.2\%); "Do you usually feel shortness of breath?" (62.5\%); "Do you usually have good memory?" (87.5\%); and "Do you keep up with your class mates in school?" (83.3\%). Further, Table 3 shows whether respiratory and postural variables of the MB group were risk or protective factors when associated with variables regarding the above-described aspects of self-perceived quality of life. Specifically, the use of accessory muscles decreased the chances of snoring at night among MB students $(p=0.03)$. Additionally, shoulder asymmetry reduced the chances of quiet sleep among MB students $(p=0.05)$ and increased their chances of coughing or feeling tired while playing or running ( $p=0.008)$. However, FHP reduced the chances of waking up at night $(p=0.04)$ and having shortness of breath $(p=0.05)$ among MB children. Sex was also considered a risk factor when related to the self-perception of MB students, as being female increased the chances of waking up at night $(p=0.02)$ and experiencing shortness of breath $(p=0.03)$.

\section{Discussion}

The results of the first stage of this study showed that individuals classified as mouth breathers exhibited significantly increased chances of thoracic breathing and the use of accessory muscles related to the persistence of MB compared to NB individuals. Previous studies suggested the presence of increased nasal resistance in $\mathrm{MB}$, which could lead to increased respiratory effort ${ }^{1,5}$. This causes the accessory inspiratory muscles to be needed, thus leading to a predominantly upper thoracic inspiratory motion ${ }^{1,5,24}$. According to Conti et al. ${ }^{24}$, there was a $42.21 \%$ prevalence of thoracic breathing in MB individuals, whereas nasal breathers exhibited a $44.35 \%$ prevalence of abdominal breathing. Additionally, Yi et al. ${ }^{6}$ have shown that MB individuals exhibited lower diaphragmatic excursion, which further required the use of the accessory muscles. Other anatomical or functional changes resulting from $\mathrm{MB}$ are associated with FHP and head extension ${ }^{7,27}$. Electromyogram studies of the cervical muscles, such as those of Ribeiro et al. ${ }^{5}$, have shown that the upper fibers of the sternocleidomastoid and upper trapezius muscles exhibit higher activity to obtain head posture control in MB individuals compared to nasal breathers during both resting and active situations. However, the postural imbalance of mouth breathers that begins in the head could be responsible for the more general involvement of the body posture due to the disorganization of the myofascial structures of the cervical and thoracic regions $^{6,7,9}$. Krakauer and Guilherme ${ }^{28}$ have shown that these postural changes become predominant 
Table 3. Relationships between respiratory and postural variables and questions of quality of life related to nasal problems, sleep, school performance and atopy in mouth breathers aged 7-14 years old, from the elementary school of Vitória, ES, Brazil.

\section{OR}

CI $95 \%$

Yes

Accessory muscles

No

2- Does your nose tend to get runny?

\section{C7-HOR-TRAGUS Distance}

\section{Anteriorization}

Normal/Rectification

3- Do you often snore at night?

Accessory muscles

Yes

No

4- Is your sleep usually calm?

Acromium-acromium

Shoulder deviation

Distance

Normal

5- Do you often wake up at night?

Gender

Female

Male

C7-HOR- TRAGUS Distance

Anteriorization

Normal/Rectification

6- Do you often complain of daytime sleepiness?

Gender

Female

Male

Accessory muscles

Yes

No

ASIS-ASIS Distance

Pelvic deviation

Normal

7- Do you often wake up with a headache?

Breathing pattern

Thoracic

Diaphragmatic

8- Do you often wake up with dry mouth?

Distance from the middle finger to the floor

NA

9- Can you follow your classes at school?

ASIS-ASIS Distance

Pelvic deviation

Normal

10- Do you usually have a good memory?

Gender

Female

Acromium-acromium

Male

Distance

Shoulder deviation

Normal
0.41

12.5

0.34

0.39

0.08

1.85

0.23

0.15

0.03

0.82

$0.03 *$

1

0.11

0.01

0.98

$0.048^{*}$

1

$-$

5.24

0.08

1

1.70

0.47

6.19

0.41

1.68

0.44

6.38

0.44

0.28

0.02

3.13

0.30

1

0.44

0.11

1.62

0.21

1

0.93

0.85

1.01

0.11

0.10

0.01

0.91

0.04*

1

$-$

0.80

73.42

0.07

0.11

0.01

1.03

0.054
$\mathbf{R}^{2}$

Logistic Regression. (-) Reference Category. $\left(^{*}\right)$ Statistically significant difference $(p<0.05)$. CI: confidence interval. NA: Not applicable. $\mathrm{R}^{2}$ coefficient of determination. Reference values: Normal angle between acromia $=0^{\circ}$ and shoulder deviation $\neq 0{ }^{\circ}$; normal angle between the anterior-superior iliac spines (ASIS-ASIS) $=0^{\circ}$ and pelvic deviation $\neq 0^{\circ}$ (Iunes et al. ${ }^{25}$ ); normal or cervical rectification: the angle between the seventh cervical vertebra, a horizontal line and the tragus (C7-HOR-TRAGUS) $>48.9^{\circ}$; head anteriorization: the angle between the seventh cervical vertebra, a horizontal line and the tragus (C7-HOR-TRAGUS) $<48.9^{\circ}$ (Raine and Twomey ${ }^{26}$ ). Source: Iunes et al..$^{25}$; Raine and Twomey ${ }^{26}$. 
Table 3. Continued...

OR

11- Do you usually cough or feel tired when you play/run?
Shoulder deviation

Normal

24.66

1

0.84

1

No

13- Do you often feel shortness of breath?
CI 95\% 2.34

0.23

-

1.11

$-$

0.01 p

$\mathbf{R}^{2}$

-

0.79

-

-

$15.48-0.03 *$

$1.020 .05^{*}$

Logistic Regression. (-) Reference Category. $\left(^{*}\right)$ Statistically significant difference $(p<0.05)$. CI: confidence interval. NA: Not applicable. ${ }^{2}$ : coefficient of determination. Reference values: Normal angle between acromia $=0^{\circ}$ and shoulder deviation $\neq 0{ }^{\circ}$; normal angle between the anterior-superior iliac spines (ASIS-ASIS) $=0^{\circ}$ and pelvic deviation $\neq 0^{\circ}$ (Iunes et al..$^{25}$ ); normal or cervical rectification: the angle between the seventh cervical vertebra, a horizontal line and the tragus (C7-HOR-TRAGUS) $>48.9^{\circ}$; head anteriorization: the angle between the seventh cervical vertebra, a horizontal line and the tragus $(\mathrm{C} 7$-HOR-TRAGUS $)<48.9^{\circ}$ (Raine and Twomey ${ }^{26}$ ). Source: Iunes et al. ${ }^{25}$; Raine and Twomey ${ }^{26}$.

in 8-year-old MB students when compared to their respective NB peers. The above authors showed that these postural imbalances were initially triggered as an adaptation to balance the action of gravity. On the other hand, Peolsson et al. ${ }^{7}$, have shown that FHP could favor other types of musculoskeletal adaptations such as increased extensor muscle activity ${ }^{29}$, which, in turn, could increase gravitational load to some cervical and thoracic motion segments $6,7,22,28,30$. In view of this information, overuse of the accessory muscles observed in MB students could cause an increase in muscle tension in the cervical segment promoting tensioning and fixings of myofascial lines ${ }^{9}$, which then leads to FHP. The persistence of the muscle tension along the other myofascial lines ${ }^{9}$ could reach other myofascial structures in the trunk and extremities, eventually triggering shoulder and pelvic asymmetry, which could, in turn, negatively affect flexibility among these individuals. The results of the present study showed that the flexibility of MB students was significantly reduced compared to their NB peers. Assuming that, in MB, the static muscles have evolved to hypertonicity and that this alteration leads to muscle shortening, this set of changes could entail loss of flexibility, especially of those muscles that do not reach the resting position during effort ${ }^{5}$.

The persistency of respiratory and postural adaptations in $\mathrm{MB}$ individuals can have a negative impact on the quality of life. In view of this observation, the second stage of this study showed the chances of these respiratory and postural adaptations in influencing the quality of life of MB students, specifically regarding their self-perceived sleep, school performance, atopy and nasal problems. The use of accessory muscles increased the chances of $\mathrm{MB}$ individuals experiencing a stuffed nose. Interestingly, allergic rhinitis is one of the main causes of airway obstruction in students and adolescents $\mathrm{s}^{31}$, suggesting that the chronic edema caused by the inflammatory process could cause a persistently stuffed nose, and due to the inflammation, the use of the accessory muscles might be a compensating adaptation that eases air intake. Given that the muscles are organized into myofascial chains ${ }^{32}$, constant physical effort of the accessory muscles might compromise other postural segments. Therefore, the other significant relationship shown in the present study was shoulder asymmetry. Specifically, this asymmetry was related to 25-fold higher chances of coughing or feeling tired during physical effort in MB students. The secondary involvement of neck and shoulder girdle muscles, influenced by accessory muscle overuse during inspiration, might be the most probable cause of shoulder asymmetry. This disorganization between cervical and thoracic posture is also known to impair pulmonary ventilation ${ }^{27}$. Ribeiro and Soares ${ }^{33}$, have shown a reduced pulmonary volume in MB individuals, in which spirometric values were below the predicted levels, with a predominance of airway obstruction. In view of these findings, the increased chances of MB individuals reporting coughing or being tired during physical activity are thought to be due to increased physical effort. 
Even though the items regarding sleep were not significant in the present study, it is important to note that the use of accessory muscles in MB individuals increased the chances of daytime sleepiness, and there was a significant decrease of their self-perception of having a quiet sleep by $88.5 \%$ for each $1 \%$ increase in shoulder asymmetry, evaluated by the lines plotted between the acromia (acromion-acromion). Studies ${ }^{34,35}$ showed that there were intercostal and upper airway dilating, muscle hypotony during sleep and, during the slow-wave sleep phase, there was reduction or even abolition of the activation reflex of the genioglossus and tensor palatine muscles. Consequently, the caliber of the upper airways was reduced, and their resistance to airflow increased ${ }^{34}$. These functional changes might promote sleep fragmentation, which is one of the causal factors of daytime sleepiness, and, thus, might recruit the accessory inspiratory muscles, as was observed in the present study.

Although studies have shown that MB is more prevalent among males ${ }^{27,31,36}$, the results of the present study show that female MB students exhibited significant relationships with $\mathrm{MB}$ effects, including a 5.2-fold increase in the chances of waking up at night, a 4.1fold greater chance of the feeling of having shortness of breath, and a tendency to daytime sleepiness, with respect to male students. It is worth mentioning that these results are in disagreement with the literature, since it is known that male individuals are more prone to MB due to the smaller size of their airways and the higher prevalence of allergic rhinitis ${ }^{31}$.

Furthermore, school failure might be related to MB and sleep disordered breathing during childhood ${ }^{13,14}$. Allergic or infectious processes, along with processes of mechanic airway obstruction, are the major causes of the above respiratory problems. Allergic rhinitis is one of the main causes of $\mathrm{MB}^{12}$ and can entail several compensatory postural adaptations. Recently, Hitos et al. ${ }^{37}$ have shown that allergic processes, which are associated with postural complications, can lead to malformation of the eustachian tube, thus decisively interfering with the loss of speech sound perception and leading to difficulties in learning to read and write. These findings are in agreement with the relationships between risk or protective factors observed in the present study, which showed that MB students with shoulder asymmetry had reduced chances for exhibiting good memory. Similarly, the MB students with pelvic asymmetry had reduced chances of keeping up with classmates in school.

This study has some limitations. The reduced final sample size was a limiting factor for statistical power, especially with respect to logistic regression. Some of the evaluations were more subjective because the study was exclusively performed in public schools. Although the literature suggests that the evaluation of a child's health-related quality of life must include information regarding both the patients' and their caregivers' perspective ${ }^{12,18}$, the self-perceived quality of life questionnaire of this study was only administered to the MB group. Specifically, the original idea of including the parents and/or legal guardians as a parameter for comparison was hampered, in part due to the lack of the involvement and adherence of the parents and/or legal guardians, who gave inaccurate answers that did not correspond with those given by their children.

\section{Conclusion}

In this study, respiratory and postural adaptations were associated with the self-perceived quality of life of MB students with respect to the variables of sleep, signs of atopy, respiratory changes and learning deficits.

The obtained results suggest that respiratory and postural adaptations, which were observed in $\mathrm{MB}$ individuals, increased the chances of persistent $\mathrm{MB}$. From another point of view, this study suggests that the association of these adaptations with the selfperception of these individuals might be related to their quality of life.

These results demonstrate that greater attention must be given to the evaluation of the MB children's point of view about their quality of life, since, in most evaluations of quality of life, the impressions of thirdparty individuals (i.e., parents and legal guardians) did not represent the real impact on the quality of life of these individuals.

\section{References}

1. Ribeiro EC, Marchiori SC, Silva AM. Electromyographic analysis of trapezius and sternocleidomastoideus muscles during nasal and oral inspiration in nasal- and mouth-breathing children. J Electromyogr Kinesiol. 2002;12(4):305-16. http:/ dx.doi.org/10.1016/S1050-6411(02)00025-1. PMid:12121687

2. Hruska RJ Jr. Influences of dysfunctional respiratory mechanics on orofacial pain. Dent Clin North Am. 1997;41(2):211-27. PMid:9142480.

3. Cuccia AM, Lotti M, Caradonna D. Oral breathing and head posture. Angle Orthod. 2008;78(1):77-82. http://dx.doi org/10.2319/011507-18.1. PMid:18193952

4. Okuro RT, Morcillo AM, Ribeiro M, Sakano E, Conti PBM, Ribeiro JD. Respiração bucal e anteriorização da cabeça: efeitos na biomecânica respiratória e na capacidade de 
exercício em crianças. J Bras Pneumol. 2011;37(4):4719. http://dx.doi.org/10.1590/S1806-37132011000400009. PMid:21881737

5. Ribeiro EC, Marchiori SC, Silva AMT. Eletromiografia dos músculos esternocleidomastóideo e trapézio em crianças respiradoras bucais e nasais durante correção postural. Arq Int Otorrinolaringol. 2003;7(1):13-9.

6. Yi LC, Jardim JR, Inoue DP, Pignatari SS. The relationship between excursion of the diaphragm and curvatures of the spinal column in mouth breathing children. J Pediatr (Rio J). 2008;84(2):171-7. PMid:18372937.

7. Peolsson A, Marstein E, McNamara T, Nolan D, Sjaaberg E, Peolsson M, et al. Does posture of the cervical spine influence dorsal neck muscle activity when lifting? Man Ther. 2014;19(1):32-6. http://dx.doi.org/10.1016/j. math.2013.06.003. PMid:23880061

8. de Arruda Falcão D, Grinfeld S, Grinfeld A, de Melo MVR. Respiradores bucais diagnosticados clinicamente e por autodiagnóstico. Consequências na postura corporal. Int J Dent. 2003;2(2):259-6.

9. Myers TW. Trilhos anatômicos: meridianos miofasciais para terapeutas manuais e do movimento. $2^{\mathrm{a}}$ ed. Rio de Janeiro: Elsevier; 2010.

10. Dezan VH, Sarraf TA, Rodacki ALF. Alterações posturais, desequilíbrios musculares e lombalgias em atletas de luta olímpica. Rev Bras Ciênc Mov. 2004;12(1):35-8.

11. Di Francesco RC, Passerotii G, Paulucci B, Miniti A. Mouth breathing in children: different repercussions according to the diagnosis. Rev Bras Otorrinolaringol (Engl Ed). 2004;70(5):665-70. http://dx.doi.org/10.1590/ S0034-72992004000500014.

12. Abreu RR, Rocha RL, Lamounier JA, Guerra AFM. Etiologia, manifestações clínicas e alterações presentes nas crianças respiradoras orais. J Pediatr. 2008;84(6):529-35. http://dx.doi. org/10.1590/S0021-75572008000700010. PMid:19060979

13. Vera CF, Conde GE, Wajnsztejn R, Nemr K. Learning disabilities and mouth breathing in subjects with attention deficit hyperactivity disorder diagnosis. Rev CEFAC. 2006;8:441-55.

14. Fensterseifer GS, Carpes O, Weckx LL, Martha VF. Mouth breathing in children with learning disorders. Braz J Otorhinolaryngol. 2013;79(5):620-4. http://dx.doi. org/10.5935/1808-8694.20130111. PMid:24141679

15. Eiser C, Morse R. The measurement of quality of life in children: past and future perspectives. J Dev Behav Pediatr. 2001;22(4):248-56. http://dx.doi.org/10.1097/00004703200108000-00007. PMid:11530898

16. Popoaski C, Marcelino TF, Sakae TM, Schmitz LM, Correa LHL. Avaliação da qualidade de vida em pacientes respiradores orais. Arq Int Otorrinolaringolog. 2012;16(1):74-81. http:// dx.doi.org/10.7162/S1809-48722012000100011.

17. Council for International Organizations of Medical Siences - CIOMS, World Health Organization - WHO. International Ethical Guidelines for Biomedical Research Involving Human
Subjects. Geneva: CIOMS; 2002. Available from: http://www. cioms.ch/frame_guidelines_nov_2002.htm

18. Godoy P, Niitsuma LEMN, Caromano FA. Functional evaluation of the buccal breather -physical therapy aspects. Arq Ciênc Saúde Unipar. 2000;4(2):111-20.

19. Magee DJ. Avaliação musculoesquelética. $5^{\text {a }}$ ed. Barueri: Manole; 2010.

20. Carregaro RL, Silva LCCB, Gil Coury HJC. Comparison between two clinical tests for the evaluation of posterior thigh muscles flexibility. Rev Bras Fisioter. 2007;11(2):13945. http://dx.doi.org/10.1590/S1413-35552007000200009.

21. Back CMZ, Lima IAX. Fisioterapia na escola: avaliação postural. Fisioter Bras. 2009;10(2):72-7.

22. Milanesi JM, Borin G, Corrêa EC, da Silva AM, Bortoluzzi DC, Souza JA. Impact of the mouth breathing occurred during childhood in the adult age: biophotogrammetric postural analysis. Int J Pediatr Otorhinolaryngol. 2011;75(8):999-1004. http://dx.doi.org/10.1016/j.ijporl.2011.04.018. PMid:21632123

23. Duarte M, Maldonado EP, Freitas AZ, Ferreira EA, Prado J, Pasqual AP, et al. Software para avaliação postural. São Paulo: Universidade de São Paulo; 2006 [cited 2013 Jul 30]. Available from:. http://sapo.incubadora.fapesp.br.

24. Conti PBM, Sakano E, Ribeiro MA, Schivinski CIS, Ribeiro JD. Assessment of the body posture of mouth-breathing children and adolescents. J Pediatr. 2011;87(4):357-63. http://dx.doi.org/10.2223/JPED.2102. PMid:21769416

25. Iunes DH, Castro FA, Salgado HS, Moura IC, Oliveira AS, Bevilaqua-Grossi D. Confiabilidade intra e interexaminadores e repetibilidade da avaliação postural pela fotogrametria. Rev Bras Fisioter. 2005;9(3):327-34.

26. Raine S, Twomey LT. Head and shoulder posture variations in 160 asymptomatic women and men. Arch Phys Med Rehabil. 1997;78(11):1215-23. http://dx.doi.org/10.1016/ S0003-9993(97)90335-X. PMid:9365352

27. Okuro RT, Morcillo AM, Sakano E, Schivinski CIS, Ribeiro MAGO, Ribeiro JD. Exercise capacity, respiratory mechanics and posture in mouth breathers. Braz J Otorhinolaryngol. 2011;77(5):656-62. http://dx.doi.org/10.1590/S180886942011000500020. PMid:22030977

28. Krakauer LH, Guilherme A. Relationship between mouth breathing and postural alterations of children: a descriptive analysis. Int J Orofacial Myology. 2000;26:1323. PMid:11307345.

29. Edmondston SJ, Sharp M, Symes A, Alhabib N, Allison GT. Changes in mechanical load and extensor muscle activity in the cervico-thoracici spine induced by sitting posture modification. Ergonomics. 2011;54(2):179-86. http://dx.doi. org/10.1080/00140139.2010.544765. PMid:21294015

30. Harms-Ringdahl K, Ekholm J, Schüldt K, Németh G, Arborelius UP. Load moments and myoelectric activity when the cervical spine is held in full flexion and extension. Ergonomics. 1986;29(12):1539-52. http://dx.doi. org/10.1080/00140138608967267. PMid:3816747

31. Barros JR, Becker HM, Pinto JA. Evaluation of atopy among mouth-breathing pediatric patients referred for treatment 
to a tertiary care center. J Pediatr. 2006;82(6):458-64. PMid:17171205.

32. Vig PS, Showfety KJ, Phillips C. Experimental manipulation of head posture. Am J Orthod. 1980;77(3):258-68. http:// dx.doi.org/10.1016/0002-9416(80)90081-0. PMid:6928735

33. Ribeiro EC, Soares LM. Avaliação espirométrica de crianças portadoras de respiração bucal antes e após intervenção fisioterapêutica. Fisioter Bras. 2003;4:163-7.

34. Katz ES, D'Ambrosio CM. Pathophysiology of pediatric obstructive sleep apnea. Proc Am Thorac Soc. 2008;5(2):253-62. http://dx.doi.org/10.1513/pats.200707-111MG. PMid:18250219

35. Abou-Khadra MK. Sleep of children living in institutional care facilities. Sleep Breath. 2012;16(3):887-94. http://dx.doi. org/10.1007/s11325-011-0592-z. PMid:21915643

36. Brant T, Parreira V, Mancini M, Becker H, Reis A, Britto R. Breathing pattern and thoracoabdominal motion in mouth-breathing children. Rev Bras Fisioter. 2008;12(6):495501. http://dx.doi.org/10.1590/S1413-35552008005000010.

37. Hitos SF, Arakaki R, Solé D, Weckx LL. Respiração oral e alteração de fala em crianças. J Pediatr. 2013;89:361-5. http://dx.doi.org/10.1016/j.jped.2012.12.007. PMid:23809686

\section{Correspondence}

Maria Teresa Martins de Araújo

Departamento de Ciências Fisiológicas

Centro de Ciências da Saúde

Universidade Federal do Espírito Santo

Avenida Marechal Campos, 1468, Maruípe Vitória, ES, Brasil

e-mail: maraujo.27@hotmail.com 